\title{
Role of dynamic hip screw with locking side plate in intertrochanteric fractures in elderly patients
}

\author{
Harjot Singh Gurudatta*, R. K. Arora, Gagan Khanna, Karandeep Singh Johal, \\ Deepinder Singh, Aditya Bhardwaj
}

Department of Orthopaedics, Sri Guru Ram Das Institute of Medical sciences and research, Amritsar, Punjab, India

Received: 15 September 2020

Revised: 30 October 2020

Accepted: 31 October 2020

\section{*Correspondence:}

Dr. Harjot Singh Gurudatta,

E-mail: harjotguruatta@gmail.com

Copyright: (c) the author(s), publisher and licensee Medip Academy. This is an open-access article distributed under the terms of the Creative Commons Attribution Non-Commercial License, which permits unrestricted non-commercial use, distribution, and reproduction in any medium, provided the original work is properly cited.

\begin{abstract}
Background: Dynamic hip screw (DHS) is a vital mainstay implant in managing intertrochanteric fractures. While most of the modifications of implant have been done in screw design, this study evaluates the role of employing locking side plate with DHS to increase the screw hold and avoid plate pull out in trochanteric fractures of elderly patients. Methods: A prospective study was conducted from August 2012 to August 2014 on 30 patients having trochanteric fractures. The fixation, fracture consequences, functional outcome and complications were assessed clinically and radiologically in immediate post-operative period and on follow-ups at six weeks, three months, six months and one year. Young patients ( $<55$ years), fractures with subtrochanteric extension and pathological fractures were excluded from study. Fractures in elderly patients from AO 31A1.1 to AO 31A3.1 were included in study. Evaluation of the clinical outcome was done by modified Harris hip score at the last follow-up.

Results: Average age of the patients in study was 64 years; males had better outcome scores, which was statistically significant. The mean trauma-surgery interval was four days. Trauma surgery interval and functional outcome by Harris hip score was statistically significant and was inversely proportional. Union was achieved in all patients with delayed union noted in four cases; the average time to union was 12.2 weeks with no major complications and good functional outcome by Harris hip score.

Conclusions: This study suggests that locking side plate with DHS would make a stronger bone implant construct and a valuable modification to prevent sliding, screw cut-out and side plate pull-out with low infection rates.
\end{abstract}

Keywords: Dynamic hip screw, Trochanteric fracture, Intertrochanteric, Locking

\section{INTRODUCTION}

Hip fractures are the most common fractures worldwide among elderly, with exponential rise witnessed owing to increased longevity of life, osteoporosis, associated comorbidities and road traffic accidents, necessitating early rigid fixation for rapid mobilization of the elderly patients to reduce the morbidity and mortality.

Sliding hip screws have been the mainstay in trochanteric fracture management because of its favorable results and low rate of non-union or hardware failure. ${ }^{1}$ In stable fracture pattern the hip screw acts only as a lateral tension band, hence less chance of fixation failure. In unstable fracture pattern it allows controlled collapse and impaction of fragments, with shortening of lever arm. However, in elderly patients, the sliding hip screw, the risk of failure of fixation is more if sliding is more, with increased incidence of cut-out of lag. ${ }^{2}$

Another significant complication associated with dynamic hip screw is the lift off of the side plate off the femur in patients with osteoporosis (Figure 1). ${ }^{3,4}$ A number of variations on the basic sliding hip screws have been done 
in past because of such complications in elderly patients, mainly concentrating on screw designs. The side plate in DHS, focus of our study, is also an important factor for anatomical and functional outcome in osteoporotic fractures. $^{5}$ The holding power of cortical screws, correlating linearly with bone mass, is so low that the chances of their loosening or breaking are considerable, considering the high stress in the implant bone construct more so in osteoporotic bones of elderly. ${ }^{6 .}$ With the introduction of fixed angle locking plate construct osteosynthesis, these shortcomings are overcome to produce a mechanically more stable and biologically better fixation with lower infection rate, due to less vascular insult.

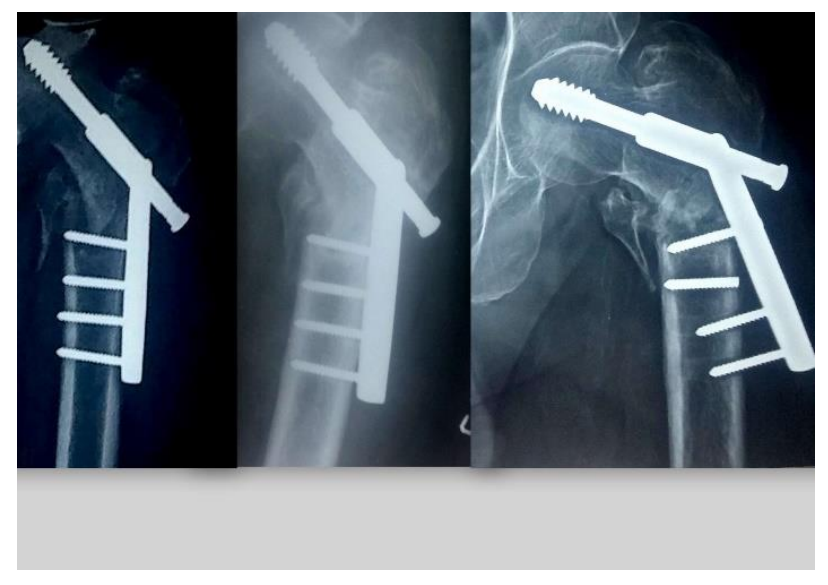

Figure 1: Plate lift off in DHS with simple plate.

In view of these advantages, this study was designed to evaluate the role of locking DHS in trochanteric fracture in elderly patients, and to study the effectiveness and complications along with clinic-radiologically union of fractures.

\section{METHODS}

This prospective study was conducted comprising of thirty patients of intertrochanteric fractures admitted in Sri Guru Ram Das institute of medical sciences and research, Amritsar during August 2012 to August 2014 who were operated with DHS with locking side plate, with proper consent and approval from ethical committee. The fixation, fracture consequences, functional outcome and complications were assessed clinically and radiologically in immediate post-operative period and on follow-ups at six weeks, three months, six months and one year. Young patients ( $<55$ years, non-osteoporotic bone), fractures with subtrochanteric extension and pathological fractures were excluded from study. Fractures in elderly patients from AO 31A1.1 to AO 31A3.1 were included in study.

Partial weight bearing was allowed after suture removal in stable fixation with range of 11-40 days. The average time of full weight bearing was 12.2 weeks. Patients were followed up for a period of twelve months. At each followup, clinical and functional assessment were done to note the movements at hip and knee, wound condition and any additional complaints. Radiographs were done at each visit to assess the status of fracture healing, callus formation at cortices, late angulations, plate pull-out, mal-union, nonunion and loss of reduction. Full weight bearing was permitted only after clinical and radiological union was evident. The patients were evaluated clinically and radiologically, with details like range of motion, limblength discrepancy, infection and deformity noted. Evaluation of the clinical outcome was done by modified Harris hip score approximated to the nearest single decimal at the last follow-up.

\section{Implant design}

The DHS consists of a lag screw that provides proximal fragment fixation and a side plate that allows this lag screw to "telescope" within its barrel. Implant sliding provides impaction which promotes union. It also decreases the moment arm and stresses on the implant. The lag screw has a standard diameter of $12.5 \mathrm{~mm}$ and is available in $5 \mathrm{~mm}$ increments from $65 \mathrm{~mm}$ to $115 \mathrm{~mm}$. The locking side plate has a minimum of 4 combi-holes for secure fixation with locking screws of $5.0 \mathrm{~mm}$ diameter.

\section{Surgical technique}

For surgery, the patient was positioned supine on the fracture table and in majority of the cases, closed reduction by manipulation with sustained traction and internal rotation gave adequate reduction. In most fractures, an anatomical reduction with posteromedial apposition was achieved satisfactorily under fluoroscopy and the fracture was internally fixed in this position using standard vastus lateralis splitting approach. A central lag screw within 10 $\mathrm{mm}$ of subchondral bone was inserted after triple reaming, followed by locking side plate application. When all screws were inserted and tightened and traction released, the fracture was compressed with a compression screw.

\section{Statistical analysis}

Statistical analysis was done by applying chi square tests, with all analysis analyses were performed using SPSS (version 17.0). A p value less than 0.05 was considered significant.

\section{RESULTS}

\section{Demographic results}

The average age of patients in the group was 64 years with male preponderance. The number of female patients increased in the eighth and ninth decade. No side predilection was noted.

The mode of injury in ninety percent was fall and thirteen patients were diagnosed with hypertension post admission, six with diabetes mellitus and other six had some systemic involvement. 


\section{Clinical parameters}

The mean trauma-surgery interval was four days. Trauma surgery interval and functional outcome by Harris hip score was statistically significant ( $p$ value $=0.019$ ) and was inversely proportional (Table 1). Closed reduction was achieved in twenty-four patients while six required open reduction. The mode of reduction was statistically not significant.

In our study, union was achieved in all patients with clinico-radiological union was evident ranging from 10 to 18 weeks. Male patients had a better functional outcome by Harris hip score, which was statistically significant ( $p$ value $=0.033$ ). Delayed union up to eighteen weeks in four patients was noted. General complications like superficial surgical site infection, decubitus ulcer, urinary tract infection and fracture site opening were noted in up to ten percent of patients and no implant related complications were noted such as cutout of lag screw, plate lift off etc. No significant limb length discrepancy was noted postoperatively. Average modified Harris hip score was 86 (Table 2).

Table 1: Trauma surgery interval.

\begin{tabular}{|llll|}
$\begin{array}{l}\text { Trauma- } \\
\text { surgery } \\
\text { interval } \\
\text { (Days) }\end{array}$ & $\begin{array}{l}\text { No. of } \\
\text { patients }\end{array}$ & $\begin{array}{l}\text { Percentage } \\
(\%)\end{array}$ & $\begin{array}{l}\text { Modified } \\
\text { Harris hip } \\
\text { score } \\
\text { (Mean) }\end{array}$ \\
\hline$<\mathbf{2}$ & 9 & 30 & 92 \\
\hline $\mathbf{3 - 6}$ & 14 & 46.66 & 86 \\
\hline $\mathbf{> 6}$ & 7 & 23.33 & 80 \\
\hline
\end{tabular}

Table 2: Modified Harris hip score at one-year followup.

\begin{tabular}{|lll|}
\hline Grading & $\begin{array}{l}\text { No. of } \\
\text { patients }\end{array}$ & $\begin{array}{l}\text { Percentage } \\
(\%)\end{array}$ \\
\hline Excellent (90-100) & 13 & 43.33 \\
\hline Good (80-90) & 13 & 43.33 \\
\hline Fair $\mathbf{( 7 0 - 8 0 )}$ & 4 & 13.33 \\
\hline Poor or failed $(<\mathbf{7 0})$ & - & - \\
\hline Average score & 86 & \\
\hline
\end{tabular}

\section{DISCUSSION}

Intertrochanteric fractures of femur in the elderly pose a great challenge in their treatment and rehabilitation and internal fixation of these fractures has been accepted as the standard procedure. The DHS remains the implant of choice for most of the surgeons. It allows controlled impaction at the fracture site, shorter operating time, no need for osteotomy, good bone healing and low rate of complications. However, use of this device in osteoporotic fractures has been reportedly associated with significant number of screw cut-outs, side plate pull-out due to linear decrease in holding power of screws in osteoporotic bone and late medialization of shaft resulting from excessive sliding of lag screw within barrel, especially in unstable intertrochanteric fractures. ${ }^{3,7}$ In our study, the use of locking side plate with dynamic hip screw has been done to observe and note the improvement in union and functional outcome in these cases (Figure 2).

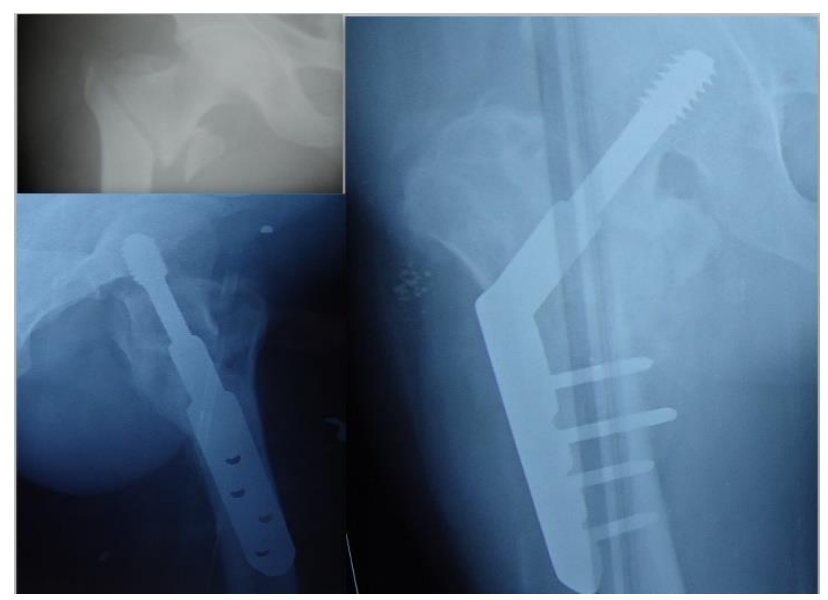

Figure 2: DHS with locking side plate.

In our study, the male to female ratio was $2: 1$, the female being $33.33 \%$. The female ratio increased in the higher age groups. There was a statistically significant relation ( $p$ value $=0.033$ ) between the gender and functional outcome, with males attaining better functional outcome in the study, which might be attributed to more sturdy male body, wider female pelvis (increased coxa vara) and more senile osteoporosis in females.

Out of 30 patients, 27 had trivial fall (90\%) and remaining three $(10 \%)$ had suffered road-traffic-accident. The tendency to fall increases with age and is exacerbated by several factors such as poor vision, decreased muscle power and decreased reflexes.

Fractures in the present study were classified as per AO/ASIF classification of trochanteric fractures. Most of the fractures for the study were stable in nature (31A $1.1=10 \%, \quad 31 \mathrm{~A} 1.2=23.33 \%, \quad 31 \mathrm{~A} 2.1=36.66 \%$, $31 \mathrm{~A} 2.2=10 \%, 31 \mathrm{~A} 2.3=16.66 \%, 31 \mathrm{~A} 3.1=3.33)$.

Most of the patients in this study reported to the hospital within a day or two of injury, while there was considerable delay in other cases. There was a statistically significant ( $p$ value $=0.019$ ) relation between the functional outcome and trauma-surgery interval. The earlier the patient got operated the better was the functional outcome.

Full weight bearing was permitted after clinic-radiological union was evident ranging from 10 to 18 weeks. In the earlier stage of bone healing, full weight bearing decreases the fracture stability. It is possible to be another cause of implant failure as well. Since partial weight bearing increases the stability of fracture site.

Delayed union was observed in four cases with time to union of around eighteen weeks. This can be accounted for 
by the fact that there was a delay of two months to surgery due to delayed presentation of the case.

The overall incidence of general complications in the present study was between three to six percent, much lower than the other previous studies. There was no chest infection or urinary tract infection post-operatively. Two of the patients had superficial infection, which resolved in a few days during the hospital stay itself. There was no deep infection or frank pus formation. This was despite the fact that twenty percent of the patients had diabetes mellitus, most of which got diagnosed on admission. This signifies the biological advantage that locking plate has over non-locking plate, as it does not compress the bone or periosteum, thereby preserving the vascularity within the bone. By preserving the vascularity, risk of the infection might be reduced. ${ }^{8}$

There was a single occurrence of a pressure sore over the back of patient, which healed with regular dressing and mobilization. This was due to asthenic built of the patient and her elderly age.

No clinically evident deep venous thrombosis was observed in any patient in the study. Absence of clinically evident deep venous thrombosis in this study indicates that early mobilization of the patient and active physiotherapy significantly reduces the incidence of deep venous thrombosis and may obviate the need of deep venous thrombosis prophylaxis.

No significant limb shortening (more than two $\mathrm{cm}$ ) was observed in the study post-operatively. Up to one $\mathrm{cm}$ of shortening can be accounted to the collapse at fracture site. This signifies the concept of fixed angle implant bone construct as provided by locking dynamic hip screw.

No case of screw cutout or varus collapse was observed in the present study. This was despite the fact that up to thirty percent of the fractures in this study were unstable and even more, osteoporotic. It has already been proven by Dylan et al that biomechanically locking DHS is a more suitable implant than conventional DHS with a significantly lower cut-out resistance, especially in elderly patients with osteoporotic bones. ${ }^{6}$ Five to ten percent of cutout have been noted with dynamic hip screw in the past.

None of the case had fixation failure due to side plate pull-out in the present study.

This signifies the advantage of locking plate over dynamic compression plate as the locking screws fixed to the plate are not dependent on holding power of screws to bone alone. ${ }^{8}$ Locking plate has biological advantages over the standard plates and avoids impairing blood supply, cancellous transformation of bone and screw loosening. Also, the risk of peri-implant fractures is therefore reduced.
Modified Harris hip score (maximum 100 points) was employed to assess the functional outcome in patients. It consists of eight questions and a physical examination. The questions are split into three categories: pain (0-44), function (0-47) and level of activity A score of 91-100 is rated as excellent, 80-90 being good, 70-79 being fair, 6069 poor and less than 60 as failed result.

The average modified Harris hip score in the present study was 86 with the range of 76.5-94.5. The patients with fair score were either towards extremes of age or had some associated systemic illness or a delayed reporting time. More than four out of five patients had good or excellent function. With DHS, Sahlstrand et al in their study had $72 \%$ good to excellent results, Juluru et al had $76 \%$, Kayali et al had $68 \%$ and Kulkarni et al had $81 \%$ good to excellent results The outcome measures have been compared with previous studies using DHS as a method of fixation as the direct correlation was not possible due to lack of more studies with DHS with locking side plate..$^{9,10}$

\section{CONCLUSION}

In the ever-progressive world of orthopedics, time has witnessed several design modifications in the mode of fixation and implants. Locking plate DHS has been proven better mechanically, and positive impact on rehabilitation and weight bearing is being observed along with a decline in the failure rates. Use of locking side plate with DHS was observed to prevent sliding, screw cut-out and side plate pull-out, which signifies the concept of fixed angle locking screws that makes a stronger implant bone construct as compared to a standard DHS and should be a better, versatile and more reliable option in management of intertrochanteric fractures.

Funding: No funding sources

Conflict of interest: None declared

Ethical approval: The study was approved by the institutional ethics committee

\section{REFERENCES}

1. Rao JP, Banzon MT, Weiss AB, Rayhack J. Treatment of unstable intertrochanteric fractures with anatomic reduction and compression hip screw fixation. Clin Orthop Relat Res. 1983;(175):65-71.

2. Davis TR, Sher JL, Horsman A. Intertrochenteric femoral fractures; Mechanical failure after internal fixation. J Bone Joint Surg Br. 1990;72B:26-31.

3. Adams CL, Robinson CM, Court-Brown CM, McQueen MM. Prospective randomized controlled trial of an intramedullary nail versus dynamic screw and plate for intertrochanteric fractures of the femur. J Orthop Trauma. 2001;15:394-400.

4. Sperner G, Wanit Schek P, Benedettok K, Glotzer W. Technical errors and early complications of osteosynthesis of pertrochantric fractures using dynamic hip screw. Unfallchirurg. 1989;92:571-6. 
5. Dean GL, David SG, Jason HN. Osteoporotic pertrochanteric hip fractures: management and current controversies. J Bone Joint Surg [Am]. 2004;86:398409.

6. Jewell DPA, Gheduzzi S, Mitchell MS, Miles AW. Locking plate increases the strength of dynamic hip screw. Injury. 2008;39(2):209-12.

7. Laohapoonrungsee A, Arpornchayanon O, Phornputkul C. Two-hole side-plate DHS in the treatment of intertrochanteric fracture: Results and complications. Injury. 2005;36(11):1355-60.

8. Gutwald R, Alpert B, Schmelzeisen R. Principle and stability of locking plates. Keio J Med. 2003;52(1):214.
9. Sahlstrand T. The Richards Compression Screw and Sliding Hip Screw System in the Treatment of Intertrochanteric Fractures. Acta Orthop Scand. 1974;45:213-9.

10. Kulkarni GS. Treatment of Trochanteric Fractures of the Hip by Modified Richard's Compressing and Collapsing Screw. Indian J Orthopaedics. 1984;18(1):30-4.

Cite this article as: Gurudatta HS, Arora RK, Khanna G, Johal KS, Singh D, Bhardwaj A. Role of dynamic hip screw with locking side plate in intertrochanteric fractures in elderly patients. Int J Res Orthop 2021;7:73-7. 